\title{
The prevalence of schizophrenia and other psychotic disorders among homeless people: a systematic review and meta- analysis
}

\author{
Getinet Ayano ${ }^{1 *}$, Getachew Tesfaw ${ }^{2}$ and Shegaye Shumet ${ }^{2}$
}

\begin{abstract}
Background: Schizophrenia and other psychotic disorders constitute a huge global burden of disease and they are major contributors to disability as well as premature mortality among homeless people. This systematic review and meta-analysis aimed to estimate the pooled prevalence of schizophrenia and other psychotic disorders among homeless people.

Methods: PubMed, Embase, and Scopus were searched to identify pertinent studies. We used a fixed- or randomeffect meta-analysis to pool data from the included studies depending on the anticipated heterogeneity. A predesigned search strategy, as well as inclusion and exclusion criteria, were used. We also performed subgroup and sensitivity analysis and Cochran's Q- and the I ${ }^{2}$ test was employed to compute heterogeneity. Egger's test and visual inspection of the symmetry in funnel plots were used to assess publication bias.

Results: Thirty-one studies involving 51,925 homeless people were included in the final analysis. The meta-analysis showed a remarkably higher prevalence of psychosis [21.21\% (95\% Cl:13.73, 31.29), $\left.{ }^{2}=99.43 \%\right]$, schizophrenia [10.29\% (95\%, Cl: 6.44, 16.02), $I^{2}=98.76 \%$, schizophreniform disorder [2.48\% (95\% Cl: 6.16, 28.11), $\left.I^{2}=88.84 \%\right]$ schizoaffective disorder $\left[3.53 \%(95 \% \mathrm{Cl}: 1.33,9.05), I^{2}=31.63 \%\right.$, ] as well as psychotic disorders not otherwise specified [9\% (95\% Cl: 6.92 , $\left.11.62), I^{2}=33.38 \%\right]$ among homeless people. The prevalence estimate of psychosis was higher in developing (29.16\%) as compared to developed (18.80\%) countries. Similarly, the prevalence of schizophrenia was highest in developing (22.15\%) than developed (8.83\%) countries.

Conclusion: This systematic review and meta-analysis revealed that schizophrenia and other psychotic disorders are highly prevalent among homeless people, indicating an urgent need for studies to help develop better mechanisms of prevention, detection as well as treatment of those disorders among homeless people.
\end{abstract}

Keywords: Homeless, Schizophrenia, Psychotic disorder, Systematic review, Meta-analysis

\section{Background}

Globally, as many as 100 million people were categorized as homeless, and over 1.6 billion individuals lacked adequate housing [1]. A wide range of multiple and interrelated factors contributes to homelessness such as domestic violence, social isolation, unemployment, addictions, mental illness, sexual assault, poverty, a critical shortage of affordable

\footnotetext{
* Correspondence: ayanogetinet@yahoo.com

${ }^{1}$ Research and Training Department, Amanuel Mental Specialized Hospital,

Addis Ababa, Ethiopia

Full list of author information is available at the end of the article
}

housing, financial difficulties, family breakdown, and adverse childhood experiences [2-6].

As compared to the general population, homeless people suffer from a greater prevalence of psychiatric disorders including schizophrenia and other psychotic disorders $[7,8]$. The reported magnitude of mental disorders among homeless people ranged from 25 to $50 \%$ across the studies [9-11]. This prevalence rate rises to about $92 \%$ among those who are street homeless [7]. The presence of mental disorders among homeless people is linked with a higher risk of disability and mortality from suicide and

(c) The Author(s). 2019 Open Access This article is distributed under the terms of the Creative Commons Attribution 4.0 International License (http://creativecommons.org/licenses/by/4.0/), which permits unrestricted use, distribution, and reproduction in any medium, provided you give appropriate credit to the original author(s) and the source, provide a link to the Creative Commons license, and indicate if changes were made. The Creative Commons Public Domain Dedication waiver (http://creativecommons.org/publicdomain/zero/1.0/) applies to the data made available in this article, unless otherwise stated. 
general medical [12-14], as well as alcohol and drugrelated causes [15].

Epidemiologic evidence from several studies has shown that schizophrenia and other psychotic disorders are among the most common psychiatric disorders among homeless people $[7,8,16]$ and they are associated with a greater risk of comorbid physical disease, substance use, and disability as well as mortality from different causes [12-14, 16-18]. The reported prevalence estimates of schizophrenia among the homeless people range from 2.29 to $60 \%$ depending on the studies $[7,8,16-22]$. The impacts of psychotic disorders among homeless people could be severe and extensive, it negatively impacts the homeless person suffering from it, the family, relatives and other population [12, 15, 23, 24].

A better understanding of the epidemiology of schizophrenia and other psychotic disorders among the homeless people could assist the development of better policies and intervention strategies as well as best intervention mechanisms to address the impacts associated with these disorders. Although there are previous systematic reviews on overall mental disorders and psychosis among homeless people, to our knowledge, this is the first systematic review and meta-analysis aimed to provide the pooled prevalence estimates of schizophrenia and other psychotic disorders among the homeless. we hypothesized that the prevalence of schizophrenia and other psychotic disorders are notably high among homeless people. Therefore, the purpose of this study was to evaluate the results of available epidemiologic studies in order to provide a high level of evidence on the global prevalence of schizophrenia and other psychotic disorders among homeless and forward implications of the findings for the future clinical practice as well as research.

\section{Methods}

\section{Research design and method}

We conduct this systematic review and meta-analysis in adherence to the PRISMA (Preferred Reporting Items for Systematic Reviews and Meta-Analyses) guidelines [25]. A predesigned protocol was utilized for searching, data abstraction, inclusion-exclusion criteria, quality evaluation, as well as data synthesis and analysis.

\section{Data source and selection process}

The electronic search was performed in the electronic databases (PubMed, Embase, and Scopus). We conducted our search in PubMed using the following terms: (schizophrenia OR schizophreniform OR schizoaffective OR psychotic disorder OR psychiatric disorder OR mental disorder)) AND (prevalence OR magnitude)) AND (homeless). Embase and Scopus were searched using specific-subjects headings suitable for the databases. We also performed a manual search to supplement our electronic database search.

\section{Inclusion and exclusion criteria}

Studies satisfying the following criteria were included in this systematic review and meta-analysis: (1) Conducted using observation study in design (cross-sectional, casecontrol or cohort studies). (2) The study population was homeless people (conducted among homeless people). (3) Estimated the prevalence of schizophrenia and other psychotic disorders or data to calculate the prevalence. Thus, commentaries, conference presentations, reviews, book reviews, and studies conducted in the nonhomeless population were excluded.

\section{Methods for data extraction and quality assessment}

Two authors (SS and GT), independently performed data abstraction from the included studies., We used predefined data extraction form to extract pertinent data from the eligible studies as advised by PRISMA guidelines [25]. The following data were extracted from all each study: author(s) name, tools used, country of the study, sample size, year of publication, and a number of positive cases, and magnitude of schizophrenia and other psychotic disorders. The quality of the studies was evaluated a modified version of the Newcastle-Ottawa Scale (NOS) [26]. The NOS grading standard is based on three main domains such as group selection (contains 4 items), comparability across the groups (one item), and assessment of exposure and outcome (4 items). The total scores including all items range from zero to nine, the highest score indicating greater quality study. The NOS has excellent test-retest reliability and inter-rater reliability ranging from poor to fair depending on the components [27].

\section{Definitions of key terms and concepts Developed and developing countries}

In this review, those countries with both longstanding established market economy as well as longstanding strong traditions in the research were considered as developed countries [28]. Thus, the USA, Canada, German, Spain, France, Scotland, the UK, Japan, and Australia were those countries, which satisfied the criteria for developed countries. Other countries such as China, Ethiopia, Ireland, and Serbia were considered as developing countries.

\section{Diagnostic definitions}

In the Diagnostic Statistical Manual of Mental disorders fifth, Edition, text revised (DSM-5), disorders having psychosis (including delusion, hallucinations, disorganized speech, and behaviors) as their primary manifestations are considered as schizophrenia and other psychotic disorders. According to this definition schizophrenia, schizoaffective, schizophreniform, delusional, brief psychotic disorders, and 
psychotic disorders due to another medical condition/substance were included under schizophrenia and other psychotic disorders [29]. We also included studies that used the previous diagnostic manual criteria such as the Diagnostic Statistical Manual of Mental disorders fourth, Edition, text revised (DSM IV) criteria [30]. Those studies that reported psychosis among homeless people without labeling the psychotic presentations under the above specific categories are considered separately as having psychosis (overall psychosis).

\section{Homelessness}

Globally, there is no consistent definition of homelessness. Some countries define homelessness as the absence of access to safe shelter and some countries define broadly including those people who are sleeping public places or designed shelter, people living in marginal accommodations (marginal housing) and rooflessness [31, 32]. In this systematic review and meta-analysis, homelessness represents the broadest definition (which is beyond rooflessness) because we have included studies, which defined homelessness in various ways.

\section{Data synthesis and analysis}

All statistical analysis was conducted by using comprehensive meta-analysis software version 3 [33]. Evaluation of the heterogeneity among the studies was performed using Cochran's Q Test and the $\mathrm{I}^{2}$ statistics [34]. The explained variance due to heterogeneity between studies was evaluated by $\mathrm{I}^{2}$ statistics [34] and the $\mathrm{I}^{2}$ indexes 25, 50 and $75 \%$ denoted low, medium and high, respectively [35]. For those studies, which were identified as heterogeneous, we conducted the analysis based on a random effect model, which is a conservative model than a fixed-effect model and is the advisable model to pool the results in the cases of heterogeneity [36]. Sensitivity and subgroup analyses were conducted based on tools used to measure schizophrenia and other psychotic disorders, the country of the study, and the quality of the studies. However, we used a fixed-effect meta-analysis for those outcomes where there is no significant heterogeneity between the studies. We used 2-tailed t-Test to evaluate whether the observed difference is statistically significant or occurred by chance. Publication bias was evaluated using a funnel plot and Egger's regression tests. All the reported probabilities were twosided and $P$-value $<0.05$ considered statistically significant.

We also conducted a meta-regression to quantify the impacts of the year of the study (studies conducted before 2010 and 2010 and above), country status (developing and developed), and, and the instrument used to measure the disorders (screening and diagnostic) on the observed heterogeneity across the studies.

\section{Results \\ Identification of studies}

Figures 1 illustrates the PRISMA flow chart of the search process. Three thousand four hundred seventeen studies were potentially detected by our electronic search engine and strategies. Additionally, we detected 7 studies by our manual search making the total studies 3424. Of these, 3294 were excluded during the assessment of duplicate and titles, as they did not meet the eligibility criteria. Our assessment of abstract in strict accordance with the inclusion and exclusion criteria resulted in the exclusion of a further 80 articles. Thus, a full-text of 50 articles were retained for further assessment and 19 of these were excluded. (Additional files 1 and 2).

\section{Characteristics of included studies}

In this systematic review and meta-analysis, a total of 31 studies [7, 20-22, 37-63] were included in the final analysis. The studies were conducted in 13 countries representing 51,925 participants. Table 1 illustrates the characteristics of the articles included in this study. Of the 31 studies, 12 were conducted in the USA [37-40, $42-44,47,49,55,58,60]$, four were conducted in Canada $[45,48,57,59]$, three conducted in German [20, 21, 41], two conducted in Ethiopia [7, 51], two conducted in France [22, 62], two conducted in Scotland) $[56,61]$, one conducted in China [63], one conducted in Spain [38], one conducted in the UK [50], one conducted in Japan [52], one conducted in Ireland [53], one conducted in Serbia [46], and one conducted in Australia [54]. The studies were published between 1984, and 2017, with the sample size ranging between 33 participants in the German and 29,143 participants in Canada.

Schizophrenia and other psychotic disorders among homeless people were predominantly measured using the DSM. The DSM was used in 18 studies, MINI in 4 studies, CIDI in 3 studies, ICD in 3 studies and the others (CANSAS, PSE, WHO-5-Jand self-report) each used in one study.

Regarding the categories of psychotic disorders reported, 18 studies assessed overall psychotic disorder, 23 assessed schizophrenia, 2 assessed schizophreniform, two assessed schizoaffective disorder, 4 assessed psychotic disorder NOS, and one assessed brief psychotic disorder.

\section{Quality of included studies}

We assessed the quality of the studies using NOS with modification. From the total, 18 studies were found to be good quality (NOS score 7 and above), and 13 studies 


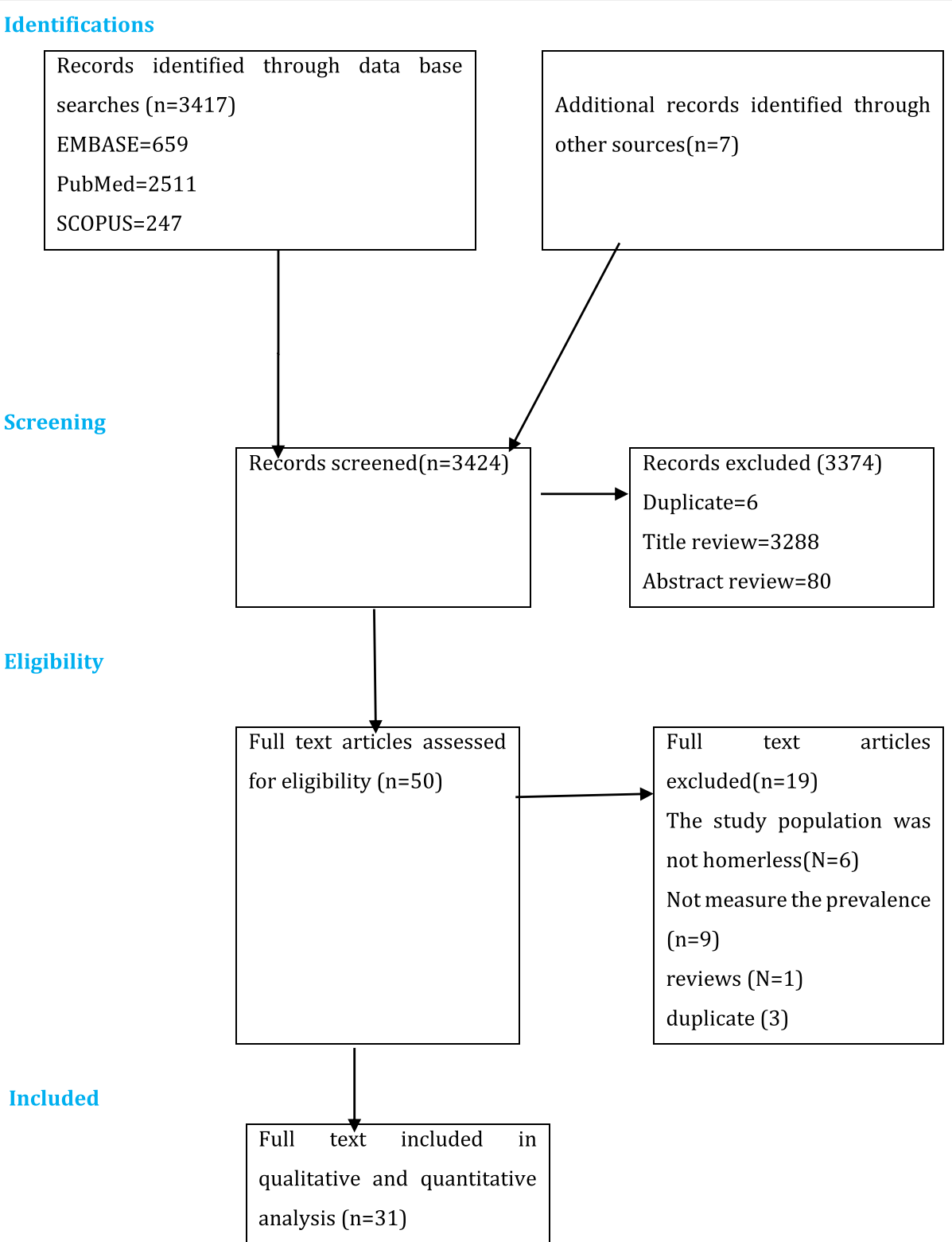

Fig. 1 PRISMA flowchart of review search. This figure shows the process of searching of pertinent studies form the three databases including identification, selection, eligibility and inclusion of the studies depending on the predefined criteria

were fair quality (NOS score between 2 and 6 inclusive) (Additional file 3).

\section{The results of a pooled meta-analysis}

\section{The prevalence of the overall psychotic disorder in} homeless people

From the total, 18 of the studies reported the prevalence of the overall psychotic disorder in homeless people (Table 1). Based on the results of the random-effects method, the pooled prevalence estimates of psychotic disorder in the homeless people was $21.21 \%$ (95\% CI; 13.73-31.29). We found significant heterogeneity for this analysis $\left(I^{2}=99.43 \% ; p<0.001\right)$ (Fig. 2).
The prevalence of schizophrenia in homeless people

In this review 24 of the studies reported the prevalence of schizophrenia among homeless people. Analysis of those studies which reported prevalence the prevalence of schizophrenia we found that the prevalence of schizophrenia was $10.29 \%$ (95\%CI 6.44-16.02). Significant heterogeneity was found for this analysis $\left(I^{2}=98.76 ; p<\right.$ 0.001) (Fig. 3).

\section{The prevalence of the schizophreniform disorder in homeless people}

From the total, 2 of the studies reported the prevalence of schizophreniform disorder in homeless people 
Table 1 Distribution of studies on psychosis in people living with homeless included in qualitative and quantitative analysis based on year, study design, sample size, instrument, country, response rate, study population and prevalence

\begin{tabular}{|c|c|c|c|c|}
\hline $\begin{array}{l}\text { Author (year) } \\
\text { (reference number) }\end{array}$ & Sample size & Tool & Country & Outcome (magnitude of psychosis) \\
\hline (Susser et al., 1989) [37] & 223 & DSM & USA & $8 \%(n=18)$ schizophrenia \\
\hline (Munoz et al., 1998) [38] & $\begin{array}{l}\text { Madrid }=262 \\
1563=\text { USA }\end{array}$ & $C|D|$ & Spain \& USA & $\begin{array}{l}\text { Madrid; } 2.4 \%(n=6) \\
\text { Los Angeles } \\
5.5 \%(n=86) \text { Schizophrenia }\end{array}$ \\
\hline (Bassuk et al., 1986) [39] & 80 & DSM & USA & $3 \%(n=2)$ Schizophrenia \\
\hline (Koegel et al., 1988) [40] & 328 & DSM & USA & $\begin{array}{l}13.7 \%(n=45) \text { Schizophrenia / schizophreniform } \\
13.1 \%(n=44) \text { schizophrenia } \\
0.6 \%(n=2) \text { schizophreniform }\end{array}$ \\
\hline $\begin{array}{l}\text { (Fichter and Quadflieg, } \\
\text { 2001) [20] }\end{array}$ & 265 & DSMIII & Germany & $\begin{array}{l}9.8 \%(n=26) \text { psychosis } \\
4.4 \%(n=12) \text { schizophrenia }\end{array}$ \\
\hline (Längle et al., 2005) [41] & 99 & ICD and DSM & Germany & $11 \%(n=7)$ Psychosis disorders \\
\hline (Connolly et al., 2008) [42] & 60 & DSM-IV & USA & $\begin{array}{l}20 \%(n=12) \text { psychosis } \\
10 \%(n=6) \text { schizophrenia } \\
5 \%(n=3) \text { schizoaffective } \\
5 \%(n=3) \text { psychosis NOS }\end{array}$ \\
\hline (Ghose et al., 2013) [43] & 2898 & ICD & USA & $3.5 \%(n=98)$ Schizophrenia \\
\hline (Tsai et al., 2014) [44] & 29,143 & DSM & USA & 9.3\%(n= 2707) Psychosis \\
\hline (Noe et al., 2016) [45] & 497 & DSM & Canada & $N=263(53 \%)$ Psychosis \\
\hline (Sarajlija et al., 2014) [46] & 104 & $I C D$ & Serbia & $\begin{array}{l}35.6 \% \text { psychosis }(n=37) \\
N=11(10.6 \%) \text { Schizophrenia }\end{array}$ \\
\hline (Ayano et al., 2017) [7] & 456 & $S C I D)$ & Ethiopia & $\begin{array}{l}\text { Schizophrenia } \\
N=274(60.09 \%) \\
\text { Psychotic disorders NOS } \\
N=45(9.87 \%)\end{array}$ \\
\hline (Schinka et al., 2012) [47] & 10,111 & DSM & USA & $\begin{array}{l}\text { Schizophrenia }=432(4.27 \%) \\
\text { Other psychosis = } 420(4.15 \%)\end{array}$ \\
\hline $\begin{array}{l}\text { (Topolovec-Vranic et al., } \\
\text { 2017) [48] }\end{array}$ & 2088 & $\mathrm{MINI}$ & Canada & $35 \%(N=731)$ Psychosis \\
\hline $\begin{array}{l}\text { (Fletcher and Reback, } \\
\text { 2017) [49] }\end{array}$ & 131 & SCID & USA & $22 \% \%(n=29)$ Psychosis \\
\hline $\begin{array}{l}\text { (Cuvee.Adams et al., } \\
\text { 1996) [50] }\end{array}$ & 64 & DSM & UK & $42 \%(n=27)$ Schizophrenia \\
\hline (Fekadu1 et al., 2014) [51] & 217 & CANSAS & Ethiopia & $\begin{array}{l}41 \%(n=89) \text { Psychosis } \\
\text { Schizophrenia }(n=79)\end{array}$ \\
\hline (Okamura et al., 2014) [52] & 346 & $\begin{array}{l}\text { WHO-Five Well-Being } \\
\text { Index (WHO-5-J) }\end{array}$ & Japan & $8.1 \%(n=28)$ Schizophrenia \\
\hline (Prinsloo et al., 2012) [53] & 38 & DSM & Ireland & $\begin{array}{l}5.3 \%(n=2) \text { Schizophrenia and Other } \\
\text { Psychotic Disorders }\end{array}$ \\
\hline (Kovess and Lazarus, 1999) [22] & 715 & CIDI & France & $\begin{array}{l}5.8 \%(n=42) \text { schizophrenic/delusional } \\
\text { disorders (certain) }\end{array}$ \\
\hline (Larney et al., 2009) [54] & 105 & Lifetime (report) & Australia & $\begin{array}{l}37.1 \%(n=39) \text { schizophrenia or other } \\
\text { psychotic disorder. }\end{array}$ \\
\hline (Fischer et al., 1986) [55] & 51 & DSM-III & USA & $2 \%(n=1)$ schizophrenia \\
\hline (Greifenhagen et.al. 1997) [21] & 32 & DSM-III & Germen & $\begin{array}{l}\text { Schizophrenic disorders } n=11 \text { (34\%) } \\
\text { Schizophrenia } n=8(25 \%) \\
\text { Schizophreniform disorder } n=3((\%)\end{array}$ \\
\hline (Newton et al., 9194) [56] & 65 & DSM & Scotland & $3 \%(n=2)$ schizophrenia \\
\hline (Bacciardi et al., 2017) [57] & 416 & $\mathrm{MINI}$ & Canada & $26 \%(n=94)$ Schizophrenia \\
\hline (Goldstein et al., 2012) [58] & 3595 & DSM \$ICD & USA & $17.6 \%(n=631)$ schizophrenia \\
\hline (Freeman et al., 1979) [59] & 250 & Present State Examination & Canada & $4.4 \%(n=11)$ schizophrenia \\
\hline
\end{tabular}


Table 1 Distribution of studies on psychosis in people living with homeless included in qualitative and quantitative analysis based on year, study design, sample size, instrument, country, response rate, study population and prevalence (Continued)

\begin{tabular}{|c|c|c|c|c|}
\hline $\begin{array}{l}\text { Author (year) } \\
\text { (reference number) }\end{array}$ & Sample size & Tool & Country & Outcome (magnitude of psychosis) \\
\hline (Bassuk et al., 1984) [60] & 78 & DSM & USA & $29.5 \%(n=23)$ Schizophrenia \\
\hline (Geddes et al., 1994) [61] & $\begin{array}{l}79 \text { in } 1966 \\
136 \text { in } 1992\end{array}$ & DSM & Scotland & $\begin{array}{l}25 \%(n=20) \text { in } 1966 \\
9 \%(n=12) \text { in } 1992 \text { Schizophrenia }\end{array}$ \\
\hline Cougnard et.al. 2006 [62] & 104 & $I C D$ & France & $32.7 \%(n=34)$ psychosis \\
\hline Yim et.al 2015 [63] & 79 & SCID & China & $\begin{array}{l}\text { Psychotic disorder 10.1\% }(n=8) \\
\text { Schizophrenia }(n=3) \\
\text { Schizoaffective }(n=1) \\
\text { Psychotic NOS }(n=4)\end{array}$ \\
\hline
\end{tabular}

(Table 1). Based on the results of the random-effects method, the pooled prevalence estimates of schizophreniform disorder in the homeless people was $2.48 \%$ (95\% CI; 0.16-28.11). We found significant heterogeneity for this analysis $\left(I^{2}=88.84 \% ; p<0.001\right)$ (Fig. 4$)$.

\section{The prevalence of the schizoaffective disorder in homeless people}

From the total, 2 of the studies reported the prevalence of schizoaffective disorder in homeless people (Table 1). Based on the results of the fixed-effects method, the pooled prevalence estimates of schizoaffective disorder in the homeless people was 3.53\% (95\% CI; 1,33-9.05).
We found no significant heterogeneity for this analysis $\left(I^{2}=31.63 \% ; p=0.227\right)$. (Fig. 5).

\section{The prevalence of psychotic disorder NOS in homeless people}

From the total, 3 of the studies reported the prevalence of psychotic disorder NOS in homeless people (Table 1). Based on the results of the fixed-effects method, the pooled prevalence estimates of psychotic disorder NOS in the homeless people was $9.00 \%$ (95\% CI; 6.92-11.62). We found no significant heterogeneity for this analysis $\left(I^{2}=33.38 \% ; p=0.223\right)$ (See Fig. 6).

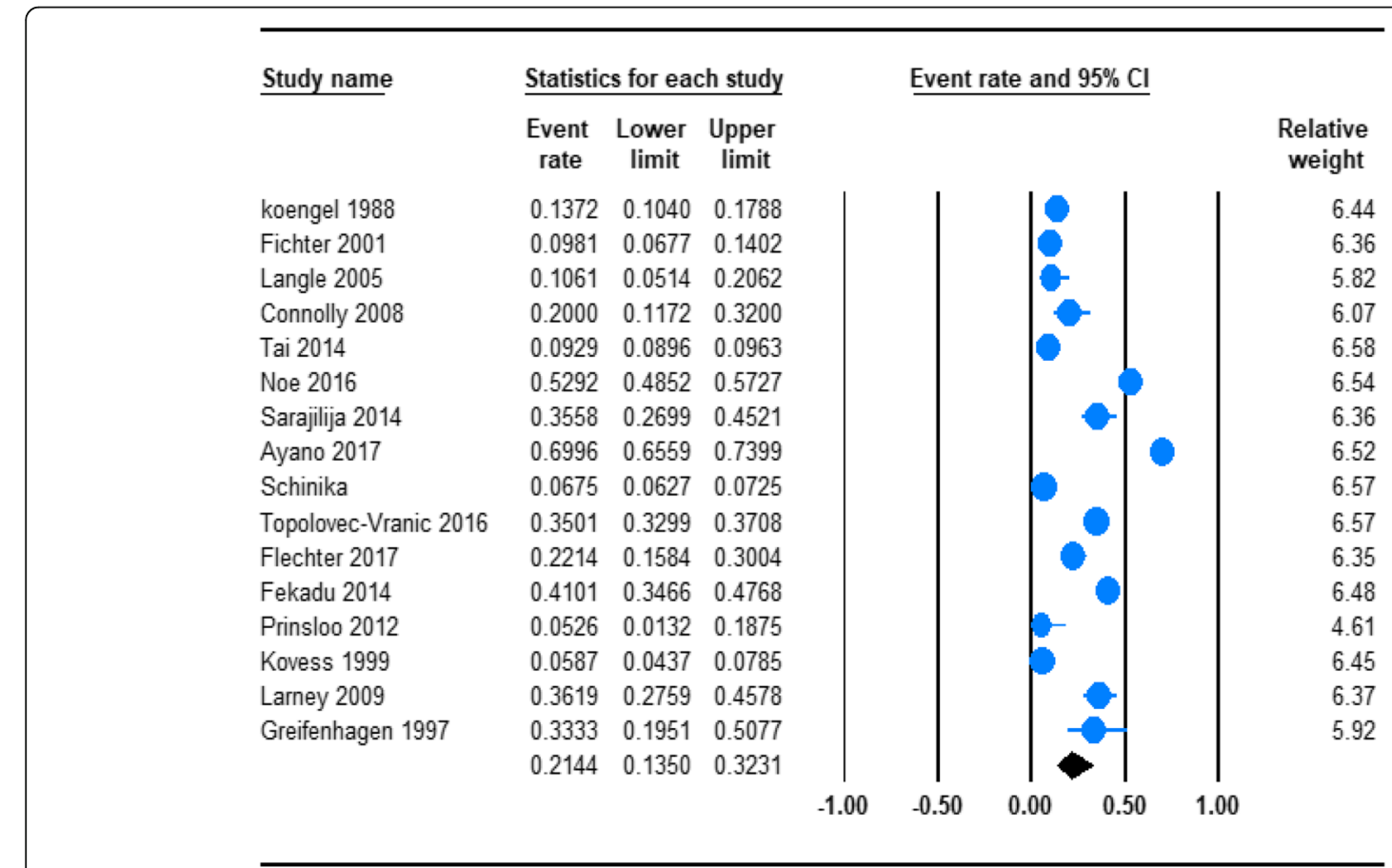

Keys: $I^{2}=99.49 \%, p<0.0001 ; \mathrm{Q}=2924.40 ; \mathrm{df}=15$; Based on random effect analysis

Fig. 2 Forest plot of the prevalence of psychosis among homeless people. The figure shows the results of the meta-analysis of the studies on psychosis on homeless people suing random effect model 


\begin{tabular}{|c|c|c|c|c|c|c|c|c|c|c|}
\hline \multirow[t]{2}{*}{ Study name } & \multicolumn{10}{|c|}{ Event rate and $95 \% \mathrm{Cl}$} \\
\hline & $\begin{array}{c}\text { Event } \\
\text { rate }\end{array}$ & $\begin{array}{c}\text { Lower } \\
\text { limit }\end{array}$ & $\begin{array}{c}\text { Upper } \\
\text { limit }\end{array}$ & & & & & & $\begin{array}{l}\text { Relative } \\
\text { weight }\end{array}$ & $\begin{array}{l}\text { Relative } \\
\text { weight }\end{array}$ \\
\hline Susser 1989 & 0.0807 & 0.0514 & 0.1245 & & & 10 & 1 & 1 & 4.51 & \\
\hline Muna $1998 s$ & 0.0229 & 0.0103 & 0.0500 & & & & & & 4.20 & \\
\hline Muna 1998u & 0.0560 & 0.0448 & 0.0675 & & & & & & 4.67 & \\
\hline Bassuk 1986 & 0.0250 & 0.0063 & 0.0945 & & & & & & 3.45 & \\
\hline koengel 1988 & 0.1341 & 0.1013 & 0.1755 & & & & & & 4.62 & \\
\hline Fichter 2001 & 0.0453 & 0.0259 & 0.0780 & & & & & & 4.43 & \\
\hline Connolly 2008 & 0.1000 & 0.0458 & 0.2053 & & & & & & 4.16 & \\
\hline Ghose 2013 & 0.0338 & 0.0278 & 0.0411 & & & & & & 4.67 & \\
\hline Sarajilija 2014 & 0.1058 & 0.0595 & 0.1810 & & & & & & 4.39 & \\
\hline Ayano 2017 & 0.6009 & 0.5652 & 0.8449 & & & & c & & 4.68 & \\
\hline Schinika & 0.0427 & 0.0390 & 0.0488 & & & & & & 4.70 & \\
\hline Adams 1996 & 0.4219 & 0.3078 & 0.5451 & & & & & & 4.50 & \\
\hline Fekadu 2014 & 0.3841 & 0.3027 & 0.4301 & & & & & & 4.64 & \\
\hline Okumara 2014 & 0.0809 & 0.0585 & 0.1147 & & & & & & 4.58 & \\
\hline Fischer 1986 & 0.0196 & 0.0028 & 0.1285 & & & & & & 2.73 & \\
\hline Greifenhagen 1997 & 0.2424 & 0.1281 & 0.4150 & & & & & & 4.21 & \\
\hline Newton 1994 & 0.0308 & 0.0077 & 0.1148 & & & & & & 3.44 & \\
\hline Bacciardi 2017 & 0.2280 & 0.1883 & 0.2887 & & & & & & 4.68 & \\
\hline Goldstein 2012 & 0.1755 & 0.1834 & 0.1883 & & & & & & 4.70 & \\
\hline Freeman 1979 & 0.0440 & 0.0245 & 0.0777 & & & & & & 4.41 & \\
\hline Bassuk 1984 & 0.2949 & 0.2045 & 0.4049 & & & & & & 4.51 & \\
\hline Geddes 1994 & 0.1488 & 0.1072 & 0.2029 & & & & & & 4.59 & \\
\hline \multirow[t]{3}{*}{ Susser et al 1989} & 0.0807 & 0.0514 & 0.1245 & & & 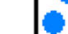 & & & 4.51 & \\
\hline & 0.1058 & 0.0885 & 0.1635 & & & & & | & & \\
\hline & & & & -1.00 & -0.50 & 0.00 & 0.50 & 1.00 & & \\
\hline
\end{tabular}

Keys: $l^{2}=98.76 \%, p<0.0001 ; Q=1767.21 ; d f=23 ;$ Based on random effect analysis

Fig. 3 forest plot of the prevalence of schizophrenia among homeless people. This figure illustrates the results of the meta-analysis of the studies on schizophrenia on homeless people suing random effect model

\section{Sensitivity analysis}

To further explore the possible source of heterogeneity in the analysis of the prevalence of psychosis in the homeless people, we conducted a sensitivity analysis by the country of origin, the instrument used to measure psychotic disorders and the quality of the included studies. When limiting the analysis to the country origin we found that the prevalence of psychotic disorder was
$18.80 \%$ for developed countries and it was $29.16 \%$ for developing countries. In these sensitivity analyses, the observed difference in the magnitude of overall psychotic disorder between the countries was not statistically significant $(P=0.313)$. Similarity to overall psychotic disorder we found no significant difference in the prevalence of schizophrenia across the countries $(P<0.001)$. The pooled prevalence estimate of schizophrenia was
Study name

$$
\begin{gathered}
\text { Event } \\
\text { rate limit limit }
\end{gathered}
$$

koengel $1988 \quad 0.00610 .00150 .0240$

Greifenhagen 19970.09090 .02960 .2468

0.02480 .00160 .2811
Event rate and $95 \% \mathrm{Cl}$

\section{Relative}

weight

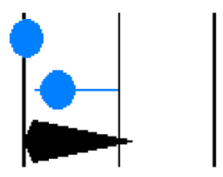

49.12

50.88

\section{$\begin{array}{lllll}-0.50 & -0.25 & 0.00 & 0.25 & 0.50\end{array}$}

Keys: $\left.\right|^{2}=88.84 \%, p=0.003 ; Q=8.96 ; d f=1$; Based on random effect analysis

Fig. 4 Forest plot of the prevalence of schizophreniform disorders among homeless people. The figure shows the results of the meta-analysis of the studies on schizophreniform disorders on homeless 
$\underline{\text { Study name }}$

$\begin{array}{lccc} & \begin{array}{c}\text { Event } \\ \text { rate }\end{array} & \begin{array}{c}\text { Lower } \\ \text { limit }\end{array} & \begin{array}{c}\text { Upper } \\ \text { limit }\end{array} \\ \text { Connolly 2008 } & 0.0500 & 0.0162 & 0.1439 \\ \text { Yim 2015 } & 0.0127 & 0.0018 & 0.0844 \\ & 0.0353 & 0.0133 & 0.0905\end{array}$

\section{Event rate and $95 \% \mathrm{Cl}$}

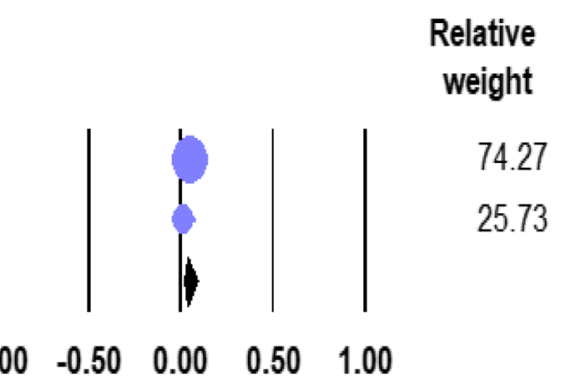

Keys: ${ }^{2}=31.63 \%, P=0.227$; Based on fixed effect analysis

Fig. 5 forest plot of the prevalence of schizoaffective disorders among homeless people. The figure shows the results of the meta-analysis of the studies on schizoaffective disorders on homeless

highest in developing countries (22.15\%) as compared with developed countries (8.83\%). In our sensitivity analysis based on the instrument used to measure psychotic disorder the pooled estimated prevalence of overall psychosis was $17.42 \%$ as measured by diagnostic instrument and it was $32.19 \%$ as measured by screening instrument, although the difference observed was not statistically significant $(P=0.256)$. The prevalence of schizophrenia was $13.20 \%$ (95\%CI 6.05-26.44) for studies conducted in or after the year 2010 and it was $8.88 \%$ (95\%CI 5.47-14.09) for studies conducted before 2010, whereas the prevalence of psychosis was $24.44 \%$ (95\%CI 13.65-29.03) for studies conducted in or after 2010 and it was $20.09 \%$ (95\% CI 10.18-28.49) for studies conducted before 2010. In fact, the observed difference in the prevalence of schizophrenia and psychosis by year of the study was not statically significant $(P=0.386$ for schizophrenia and $P=0.392$ for psychosis). Finally, we also conducted the sensitivity analysis based on the quality of included studies, the prevalence of overall psychotic disorder was found relatively equal for good quality $(21.37 \%)$ and fair quality studies $(22.67 \%)$, and the difference was not statistically significant $(P=0.868)$. (Table 2$)$.

\section{Meta-regression}

We first conducted an initial univariate regression analysis, which guided the selection of the independent variables to include in the final meta-regression model. As
Study name

$\begin{array}{lccc} & \begin{array}{c}\text { Event } \\ \text { rate }\end{array} & \begin{array}{c}\text { Lower } \\ \text { limit }\end{array} & \begin{array}{c}\text { Upper } \\ \text { limit }\end{array} \\ \text { Connolly 2008 } & 0.0500 & 0.0162 & 0.1439 \\ \text { Ayano 2017 } & 0.0987 & 0.0745 & 0.1296 \\ \text { Yim 2015 } & 0.0506 & 0.0191 & 0.1273 \\ & 0.0900 & 0.0692 & 0.1162\end{array}$

Event rate and $95 \% \mathrm{Cl}$

$$
\begin{array}{r}
\text { Relative } \\
\text { weight } \\
6.04 \\
85.92 \\
8.04
\end{array}
$$$$
|+|
$$

Keys: $\mathrm{l}^{2}=33.38 \%, \mathrm{P}=0.223$; Based on fixed effect analysis

Fig. 6 Forest plot of the prevalence of psychotic disorders NOS among homeless people. The figure shows the results of the meta-analysis of the studies on psychotic disorders not otherwise specified (NOS) on homeless 
Table 2 Sensitivity analysis of all studies based on the country of origin, the instrument used, and study quality of the included studies

\begin{tabular}{|c|c|c|c|c|c|c|c|}
\hline \multirow[t]{2}{*}{ Subgroups } & \multirow[t]{2}{*}{ Studies, n } & \multirow[t]{2}{*}{ Prevalence (\%) } & \multirow[t]{2}{*}{$95 \% \mathrm{Cl}$} & \multirow[t]{2}{*}{ Disorder type } & \multicolumn{2}{|c|}{ Heterogeneity across the studies } & \multirow{2}{*}{$\begin{array}{l}\text { Heterogeneity between } \\
\text { groups ( } P \text {-value) }\end{array}$} \\
\hline & & & & & $\overline{1^{2}}$ & $P$-value & \\
\hline \multicolumn{8}{|l|}{ Country } \\
\hline Developed & 13 & 18.80 & $11.90-28.41$ & \multirow[t]{2}{*}{ Overall psychotic disorder } & 99.42 & $<0.001$ & \multirow[t]{2}{*}{0.313} \\
\hline Developing & 5 & 29.16 & $13.39-52.28$ & & 99.92 & $<0.001$ & \\
\hline \multicolumn{8}{|l|}{ Instrument used } \\
\hline Screening & 5 & 32.19 & $13.51-59.08$ & \multirow[t]{2}{*}{ Overall psychotic disorder } & 98.97 & $<0.001$ & \multirow[t]{2}{*}{0.256} \\
\hline Diagnostic & 13 & 17.42 & $8.26-30.08$ & & 99.78 & $<0.001$ & \\
\hline \multicolumn{8}{|l|}{ Quality of studies } \\
\hline High & 9 & 21.37 & $11.50-36.24$ & \multirow[t]{2}{*}{ Overall psychotic disorder } & 99.71 & $<0.001$ & \multirow[t]{2}{*}{0.868} \\
\hline Fair & 9 & 22.60 & $16.22-30.57$ & & 79.34 & $<0.001$ & \\
\hline \multicolumn{8}{|l|}{ Country } \\
\hline Developed & 19 & 8.83 & $4.28-13.64$ & \multirow[t]{2}{*}{ Schizophrenia } & 98.06 & $<0.001$ & \multirow[t]{2}{*}{0.080} \\
\hline Developing & 4 & 22.15 & $1.83-43.98$ & & 97.22 & $<0.001$ & \\
\hline \multicolumn{8}{|l|}{ Year } \\
\hline Before 2010 & 14 & 8.88 & $5.47-14.09$ & \multirow[t]{2}{*}{ Schizophrenia } & 92.59 & $<0.001$ & \multirow[t]{2}{*}{0.386} \\
\hline 2010 and above & 9 & 13.20 & $6.05-26.44$ & & 99.49 & $<0.001$ & \\
\hline \multicolumn{8}{|l|}{ Year } \\
\hline Before 2010 & 8 & 20.09 & $10.18-28.49$ & \multirow[t]{2}{*}{ Psychosis } & 93.92 & $<0.001$ & \multirow[t]{2}{*}{0.392} \\
\hline 2010 and above & 10 & 24.44 & $13.65-29.03$ & & 99.68 & $<0.001$ & \\
\hline
\end{tabular}

recommend all variables with $P$-value $<0.8$ were included in the final regression analysis [64]. The impacts of year (studies conducted before 2010 and 2010 and above), country status (developing and developed), and, and instrument used to measure the disorders (screening and diagnostic) were quantified in the meta-regression model. The analysis was conducted for both schizophrenia and psychosis. The overall proportion of variance explained by the above covariates in the final model was $23 \%$ for schizophrenia $\left(R^{2}=23 \%\right.$; $P$ value $\left.=0.5880\right)$ and its was $0.0 \%$ for psychosis $\left(R^{2}=0.0 \%\right.$; $P$ value $\left.=0.4415\right)$. All three covariates such as year, country status and diagnostic instruments were not statistically significant determinants for the observed variation in the prevalence across studies for both psychosis and schizophrenia. (Additional files 4 and 5).

\section{Publication bias}

The funnel plot was symmetric and Egger's regression tests provided no evidence of substantial publication bias for the prevalence of overall psychotic disorder $(B=6.94$, $\mathrm{SE}=3.83, P=0.089)$ as well as schizophrenia $(\mathrm{B}=0.276$, $\mathrm{SE}=2.84, P=0.923$ ). (Fig. 7 and 8 ).

\section{Discussion}

To the best of our knowledge, this is so far the first study to systematically search, assess, and synthesize the estimated poled prevalence of schizophrenia and other psychotic disorders among homeless people. We conducted a systematic review and meta-analysis over 31 studies on the prevalence of schizophrenia and other psychotic disorders among homeless people. Our analysis resulted in a remarkably higher prevalence of overall psychosis $(21.21 \%)$, schizophrenia (10.29\%), schizophreniform disorder (2.48\%), schizoaffective disorder (3.53\%), as well as psychotic disorders not otherwise specified (9\%) among homeless people The findings of our meta-analysis highlighted that the prevalence of schizophrenia and other psychotic disorders were higher among homeless people as compared to the reported prevalence in the general population. These findings underline schizophrenia and other psychotic disorders as a significant and serious global public health issue among homeless people.

The present systematic review and meta-analysis revealed that the existing epidemiologic data on the prevalence of schizophrenia and other psychotic among homeless people demonstrated a considerable difference based on the country (the origin of the study), the tools used to quantify schizophrenia and other psychotic disorders, and the reported quality of the studies. The majority of the included articles were performed in developed countries $(87.1 \% ; n=27)$ and only a small number of studies were conducted in developing countries $(12.90 \%$; $n=$ $4)$. To quantify the magnitude of schizophrenia and other 


\section{Funnel Plot of Standard Error by Logit event rate}

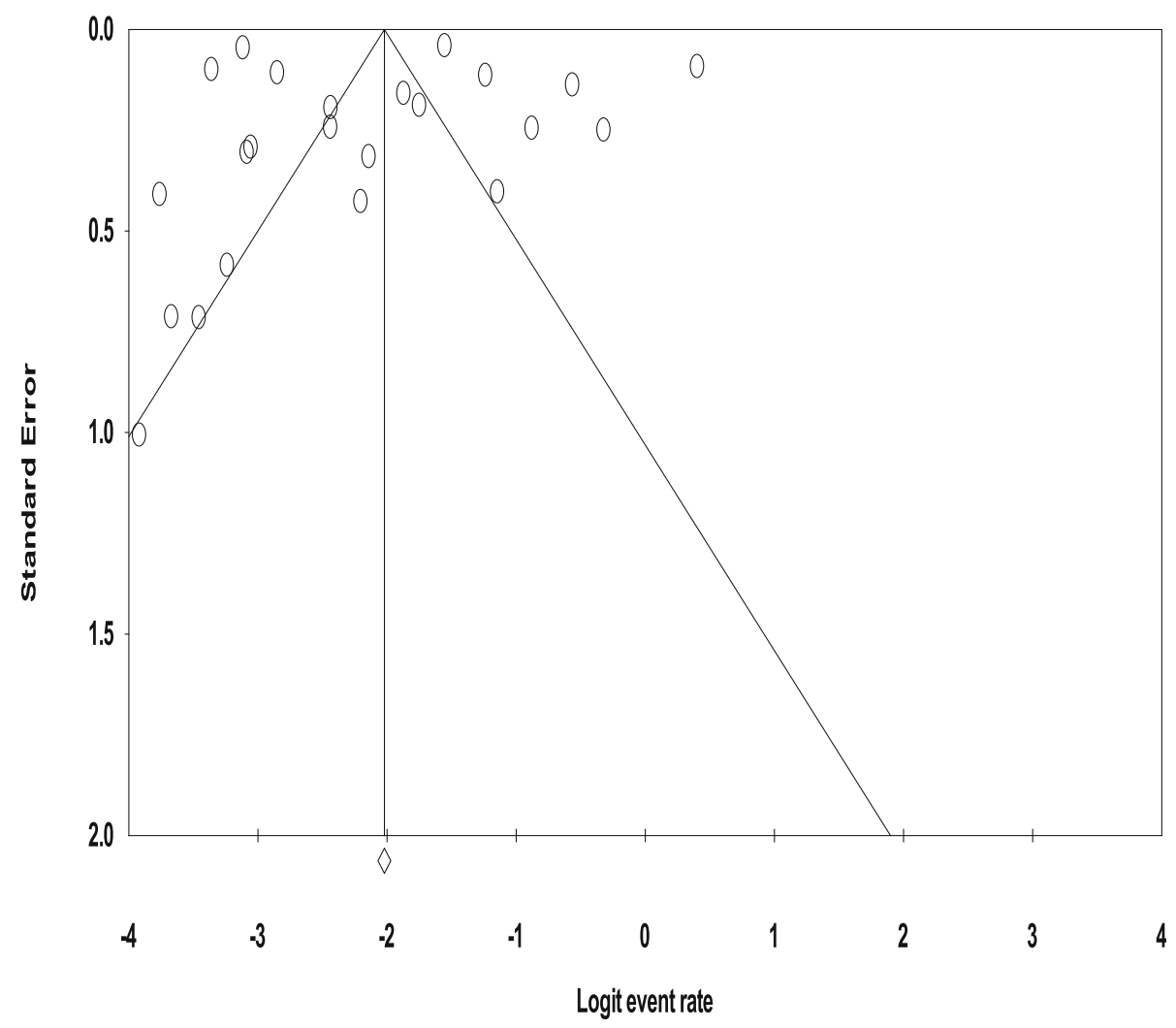

Fig. 7 Publication bias for schizophrenia among homeless people

psychotic among the homeless, some of the articles used screening tools and some used diagnostic instruments.

The results of our study underlined that the prevalence estimates of overall psychosis (21.21\%) were remarkably higher than the previous systematic review reports from western countries among the homeless (12.7\%) [65]. The possible reasons for the observed difference includes: first, the previous review considered specific categories of psychotic disorders including schizophrenia, schizoaffective and other distinct categories of psychotic disorders as psychosis which obviously underestimates the estimated prevalence whereas in the current meta-analysis, studies that reported the estimate of overall psychosis only were included under psychosis analysis and for articles that reported the specific categories of psychotic disorder we conducted separate analysis; second, the present review included studies from developed as well as developing countries whereas the previous study was conducted only in western countries and in our subgroup analysis we found that the magnitude of psychosis in developed countries was lower than that of developing countries. Therefore, the possible reason for the higher magnitude of psychosis in the previous study may be due to the inclusion of new studies including studies from developing countries.
The pooled prevalence estimates of schizophrenia in the general population have been found to be $(0.4 \%)$ [66], and the pooled prevalence estimates in the current study exceed this estimate more than 25 fold (10.29\%). The current systematic review and meta-analysis also resulted in a remarkably greater prevalence of schizophreniform disorder (2.48\%), schizoaffective disorder (3.53\%), and any psychosis (21.21\%) among the homeless. These results are higher than the reported prevalence in the general population [67]. There are a range of explanations for the observed remarkable difference in the magnitude of schizophrenia between homeless people and general populations: First, the presence of a considerably higher prevalence rates of serious physical health problems such as tuberculosis, HIV/AIDS and other medical conditions possibly could contribute to the greater prevalence of psychiatric disorders including schizophrenia among the homeless people [23, 68-72]; second, evidence shows that homeless people are more likely to experience traumatic events including physical and sexual abuse, which has been linked with greater risks of mental health problems including psychotic disorders in those who are exposed [73-76]; thirdly, the presence of considerably higher magnitude of mental, neurologic and substance use disorders among homeless 


\section{Funnel Plot of Standard Error by Logit event rate}

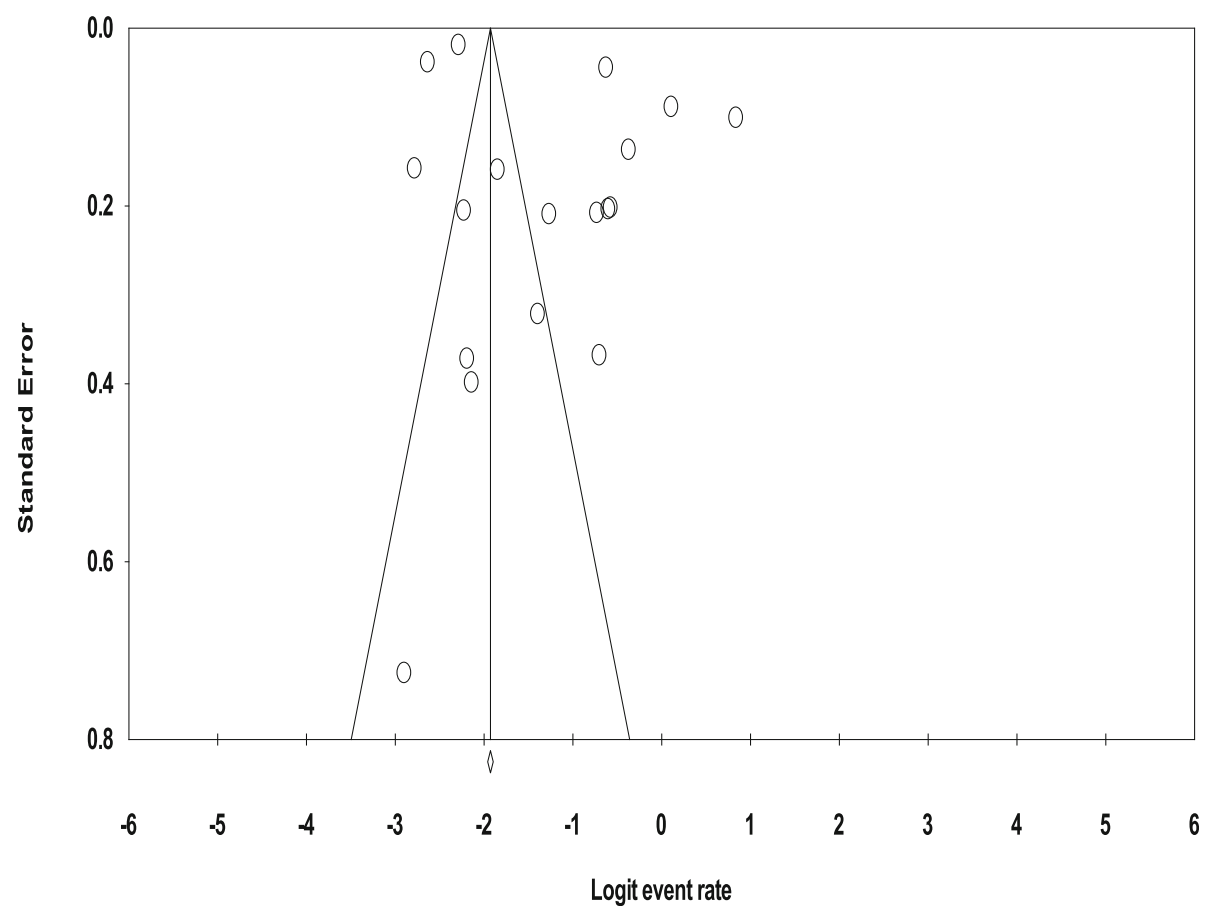

Fig. 8 Publication bias for psychosis among homeless people

people including anxiety, depressive, bipolar, and other psychiatric and substance use disorder among homeless people as compared with other populations are the other possible reasons for the observed high prevalence of schizophrenia among the homeless [7, 8, 40, 77].

This review revealed the highest prevalence of schizophrenia and other psychotic disorders was higher in developing countries than in developed countries. There are many interpretations of the observed variation in the magnitude of schizophrenia and other psychotic disorders among homeless people among the countries. (1), the possible methodologic variations such as the tools utilized to quantify schizophrenia and other psychotic disorders among the included studies is the possible reason for the observed considerable difference. For instance, in our subgroup analysis according to the tools used we found we found a remarkably high prevalence of psychosis as measured by screening instrument (32.19\%) than diagnostic instruments $(17.42 \%)$; (2) the possible variations in in the magnitude of the potential contributing factors that increase the risk of schizophrenia and other psychotic disorders among the study participants across the countries including potential life treating traumatic events and disasters and serious physical health problems are the other possible explanations for the observed variation in the magnitude of schizophrenia and other psychotic disorders across the nations; (3) the variations in the severity of the disease and comorbid other psychiatric and substance-related disorders among homeless people across the countries are the other potential reasons for the observed difference. In fact, the observed the difference in magnitude of schizophrenia psychosis among the developed and developing countries was not statically significant. Therefore, the difference is a chance of finding rather than a real difference. Additionally, the lower number of studies in developing countries as compared with developed countries must be considered. Finally, the inclusion of studies conducted on-street homeless in developing countries than developed might overestimated the prevalence.

\section{Strength and limitations}

The present systematic review and meta-analysis had numerous strengths: First, the study utilized predefined procedure for searching selection of the articles, data extraction as well as analysis; second, the extradition of information from the included articles and quality evaluation were performed by two independent; third, we conducted a subgroup and sensitivity analysis based on the country of the study, the tools used, and the quality of the studies. Finally, we also conducted a meta-regression analysis to 
quantify the impacts of important covariates such as year of study, the status of the country and instruments used to quantify psychotic disorders. The meta-regression provided no evidence of a significant effect by all of the above covariates.

However, this review also had some limitation: first, most of the included studies were conducted in developed countries and only 4 studies were conducted in developing countries; second, we included small number of articles a subgroup and sensitivity analysis which could possibly reduce the power of the estimate; third, we observed a considerable heterogeneity across the studies.

\section{The implication of the findings for future research and clinical practice}

This study has found some implication for the future clinical practice as well as research; Firstly, we found a higher magnitude of schizophrenia and other psychotic disorders among homeless people as compared to the reported magnitude in the general population, which needs further strong studies to explore the possible reasons for the higher magnitude. Secondly, we found a few numbers of studies that estimated the prevalence of schizophrenia and other psychotic disorders in developed countries. So, further studies are required to understand the prevalence of schizophrenia and other psychotic disorders in developing countries and compare them with the prevalence estimate from developed countries. Thirdly, attention need to give by the concerned bodies to address schizophrenia and other psychotic disorders among homeless people including better ways of prevention and treatment strategies possibly integrating the mental health service of the homeless with the existing medical services, which suggests utilizing holistic approaches to address the health needs of the homeless people such as physical, mental, and substance use problems as well as suicide.

\section{Conclusion}

In conclusion, the current systematic review and metaanalysis revealed that the prevalence of schizophrenia and other psychotic disorders are notably high among homeless people. The meta-analysis also showed a higher prevalence of both psychosis and schizophrenia in developing countries as compared to developed countries. Robust studies determining the possible reasons for the higher magnitude of schizophrenia and other psychotic disorders among the homeless were warranted. Moreover, there is an urgent need for robust and informative studies to help develop better mechanisms of prevention, detection as well as treatment of those disorders among homeless people.

\section{Supplementary information}

Supplementary information accompanies this paper at https://doi.org/10. 1186/s12888-019-2361-7.

Additional file 1. Screenshot of document results from the three databases. This additional material shows snapshot of number of studies identified during the database search PubMed $(n=2511)$, Embase $(n=$ 659), and Scopus ( $n=247)$

Additional file 2. Excluded full text articles with reasons of exclusion. The reasons for the excluded full text articles includes: (1) not reported prevalence; (2) reviews; (3) duplicate; (4) not conducted on homeless people.

Additional file 3. The Quality of the included studies based on the NOS quality score, a 9 point score. Score 7 and above represented good quality; 2 to 6 represented fair quality; and 0 and 1 represented poor quality.

Additional file 4. Meta-regression of the prevalence of psychosis among the homeless based on year, tools used and country status.

Additional file 5. Meta-regression of the prevalence of schizophrenia among the homeless based on year, tools used and country status.

\section{Abbreviations}

AIDS: Acquired Immune Deficiency Syndrome; CANSAS: Camberwell Assessment of Need Short Appraisal Schedule; CIDI: Composite International Neuropsychiatric Interview; DSM IV-TR: Diagnostic Statistical Manual of Mental disorders fourth, Edition, text revised; DSM-5-TR: Diagnostic Statistical Manual of Mental disorders fifth, Edition, text revised; HIV: Human Immune Deficiency Virus; ICD: International Classification of Disease; MINI: Mini International Neuropsychiatric Interview; NOS: Newcastle-Ottawa Scale; PRISMA: Preferred Reporting Items for Systematic Reviews and MetaAnalyses; PSE: Present State Examination; UK: United Kingdom; USA: United States of America; WHO: World Health Organization

\section{Acknowledgments}

We are delighted to acknowledge all the authors from the included studies.

\section{Authors' contributions}

The author (GA) conceptualized the study, conducted analyses, write-up and approval of the final manuscript. GT was performed the search, data extraction, quality assessment, write the discussion, draft and approved the final manuscript. SS was participated in discussion and consensus and approved the final manuscript.

\section{Funding}

The authors declare that there is no funding.

Availability of data and materials

All data generated or analyzed during this study are included in this article.

Ethics approval and consent to participate

$\mathrm{N} / \mathrm{A}$

\section{Consent for publication}

N/A

\section{Competing interests}

The authors declare that they have no competing interests.

\section{Author details}

${ }^{1}$ Research and Training Department, Amanuel Mental Specialized Hospital, Addis Ababa, Ethiopia. ${ }^{2}$ Department of Psychiatry, College of Medicine and Health Sciences, University of Gondar, Gondar, Ethiopia.

Received: 11 June 2019 Accepted: 15 November 2019

Published online: 27 November 2019

References

1. Foundation: HWC. Global hoelessness statistics, 2015. 2015. 
2. Habánik T. Mental health problems as one of the factors in the development and persistence of homelessness. Kontakt. 2018;20(2):e171-e6.

3. Nishio A, Horita R, Sado T, Mizutani S, Watanabe T, Uehara R, et al. Causes of homelessness prevalence: relationship between homelessness and disability. Psychiatry Clin Neurosci. 2017;71(3):180-8.

4. Mabhala MA, Yohannes A, Griffith M. Social conditions of becoming homelessness: qualitative analysis of life stories of homeless peoples. Int J Equity Health. 2017;16(1):150.

5. Tsai J, Rosenheck RA. Risk factors for homelessness among US veterans. Epidemiol Rev. 2015;37:177-95.

6. Caton CL, Shrout PE, Eagle PF, Opler LA, Felix A. Correlates of codisorders in homeless and never homeless indigent schizophrenic men. Psychol Med. 1994;24(3):681-8.

7. Ayano G, Assefa D, Haile K, Chaka A, Solomon H, Hagos P, et al. Mental, neurologic, and substance use (MNS) disorders among street homeless people in Ethiopia. Ann General Psychiatry. 2017;16:40.

8. Fazel S, Khosla V, Doll H, Geddes J. The prevalence of mental disorder among the homeless in western countries: systematic review and metaregression analysis. PLoS Med. 2008;5(12):e225.

9. Scott J. Homelessness and mental illness. Br J Psychiatry. 1993;162:314-24.

10. Breakey WR, Fischer PJ, Kramer M, Nestadt G, Romanoski AJ, Ross A, et al. Health and mental health problems of homeless men and women in Baltimore. JAMA. 1989:262(10):1352-7.

11. Gelberg L, Linn LS. Demographic differences in health status of homeless adults. J Gen Intern Med. 1992;7(6):601-8.

12. Babidge NC, Buhrich N, Butler T. Mortality among homeless people with schizophrenia in Sydney, Australia: a 10-year follow-up. Acta Psychiatr Scand. 2001;103(2):105-10.

13. Hwang SW. Mortality among men using homeless shelters in Toronto, Ontario. JAMA. 2000;283(16):2152-7.

14. Prigerson HG, Desai RA, Liu-Mares W, Rosenheck RA. Suicidal ideation and suicide attempts in homeless mentally ill persons: age-specific risks of substance abuse. Soc Psychiatry Psychiatr Epidemiol. 2003;38(4):213-9.

15. Barrow SM, Herman DB, Cordova P, Struening EL. Mortality among homeless shelter residents in New York City. Am J Public Health. 1999;89(4): 529-34.

16. Smith EM, North CS, Spitznagel EL. Alcohol, drugs, and psychiatric comorbidity among homeless women: an epidemiologic study. J Clin Psychiatry. 1993;54(3):82-7.

17. Landefeld JC, Miaskowski C, Tieu L, Ponath C, Lee CT, Guzman D, et al. Characteristics and factors associated with pain in older homeless individuals: results from the health outcomes in people experiencing homelessness in older middle age (HOPE HOME) study. J Pain. 2017;18(9):1036-45.

18. Bender K, Brown SM, Thompson SJ, Ferguson KM, Langenderfer L. Multiple victimizations before and after leaving home associated with PTSD, depression, and substance use disorder among homeless youth. Child Maltreat. 2015:20(2):115-24.

19. Taylor KM, Sharpe L. Trauma and post-traumatic stress disorder among homeless adults in Sydney. Aust N Z J Psychiatry. 2008:42(3):206-13.

20. Fichter MM, Quadflieg N. Prevalence of mental illness in homeless men in Munich, Germany: results from a representative sample. Acta Psychiatr Scand. 2001;103(2):94-104.

21. Greifenhagen A, Fichter M. Mental illness in homeless women: an epidemiological study in Munich, Germany. Eur Arch Psychiatry Clin Neurosci. 1997:247(3):162-72.

22. Kovess $V$, Mangin LC. The prevalence of psychiatric disorders and use of care by homeless people in Paris. Soc Psychiatry Psychiatr Epidemiol. 1999; 34(11):580-7.

23. Martens WH. A review of physical and mental health in homeless persons. Public Health Rev. 2001;29(1):13-33.

24. North CS, Smith EM, Spitznagel EL. Violence and the homeless: an epidemiologic study of victimization and aggression. J Trauma Stress. 1994;7(1):95-110.

25. Moher D, Shamseer L, Clarke M, Ghersi D, Liberati A, Petticrew M, et al. Preferred reporting items for systematic review and meta-analysis protocols (PRISMA-P) 2015 statement. Syst Rev. 2015;4(1):1.

26. Stang A. Critical evaluation of the Newcastle-Ottawa scale for the assessment of the quality of nonrandomized studies in meta-analyses. Eur J Epidemiol. 2010;25(9):603-5.

27. Oremus M, Oremus C, Hall GB, McKinnon MC. Inter-rater and test-retest reliability of quality assessments by novice student raters using the Jadad and Newcastle-Ottawa Scales. BMJ Open. 2012;2(4):1-6.
28. Division. UNS. Composition of macro geographical (continental) regions, geographical sub-regions, and selected economic and other groupings. 2012. http://unstats.un.org/unsd/methods/m49/m49regin.htm.

29. American Psychiatric Association. Diagnostic Stastistical Manual of Mental Disorder. 5th ed; 2013

30. American Psychiatric Association. Diagnostic and statistical manual of mental disorders-IV-TR. Washington, DC: American Psychiatric Association; 2000

31. Chamberlain C, Johnson G, Robinson C, editors. Homelessness in Australia: an introduction. New South Wales: NewSouth Publishing; 2014.

32. Clifford B, Wilson A, Harris P. Homelessness, health and the policy process: a literature review. Health Policy. 2019;123(11):1125-32.

33. Borenstein M. Comprehensive meta-analysis software (beta-version). Englewood: BioStat; 2005.

34. Borenstein $M$, Hedges LV, Higgins JP, Rothstein HR. A basic introduction to fixed-effect and random-effects models for meta-analysis. Res Synth Methods. 2010;1(2):97-111.

35. Higgins JP, Thompson SG, Deeks JJ, Altman DG. Measuring inconsistency in meta-analyses. BMJ. 2003:327(7414):557-60.

36. Riley RD, Higgins JP, Deeks JJ. Interpretation of random effects metaanalyses. BMJ. 2011;342:d549.

37. Susser E, Struening EL, Conover S. Psychiatric problems in homeless men. Arch Gen Psychiatry. 1989:46:845-50.

38. Munoz M, Vazquez C, Koegel P, Sanz J, Burnam MA. Differential patterns of mental disorders among the homeless in Madrid (Spain) and Los Angeles (USA). Soc Psychiatry Psychiatr Epidemiol. 1998;33:514-20.

39. BASSUK EL, RUBIN L, LAURIAT AS. Characteristics of sheltered homeless families. Am J Public Health. 1986:76:1097-101.

40. Koegel P, Burnam MA, Farr RK. The prevalence of specific psychiatric disorders among homeless individuals in the Inner City of Los Angeles. Arch Gen Psychiatry. 1988;45(12):1085-92.

41. Längle G, Egerter B, Albrecht F, Petrasch M, Buchkremer G. Prevalence of mental illness among homeless men in the community approach to a full census in a southern German university town. Soc Psychiatry Psychiatr Epidemiol. 2005;40:382-90

42. Connolly AJ, Cobb-Richardson P, Ball SA. Personality disorders in homeless drop-in center clients. J Personal Disord. 2008;22(6):573-88.

43. Ghose T, Fiellin DA, Gordon AJ, Metrauxd S, Goetz MB, Blackstock O, Mclnnes K, et al. Hazardous drinking and its association with homelessness among veterans in care. Drug Alcohol Depend. 2013;131:202-6.

44. Tsai J, Kasprow WJ, Rosenheck RA. Alcohol and drug use disorders among homeless veterans: prevalence and association with supported housing outcomes. Addict Behav. 2014;39:455-60.

45. Noe F, Moniruzzaman A, Somers J, Frankish J, Strehlau V, Schiitz C, et al. A longitudinal study of suicidal ideation among homeless, mentally ill individuals. Soc Psychiatry Psychiatr Epidemiol. 2016;51:107-14.

46. Sarajlija M, Jugovic A, Živaljevic D, Merdovic B, Sarajlija A. Assessment of health status and quality of life of homeless persons in Belgrade, Serbia. Vojnosanit Pregl. 2014;71(2):167-74.

47. Schinka JA, Schinka KC, Casey RJ, Kasprow W, Bossarte RM. Suicidal Behavior in a National Sample of Older Homeless Veterans. Am J Public Health. 2012; 102(S1):147-53.

48. Topolovec-Vranic J, Schuler A, Gozdzik A, Somers J, Bourque PE, Frankish CJ, et al. The high burden of traumatic brain injury and comorbidities amongst homeless adults with mental illness. J Psychiatr Res. 2017:87:53-60.

49. Fletcher JB, Reback CJ. Mental health disorders among homeless, substance-dependent men who have sex with men. Drug Alcohol Rev. 2017;36:555-9.

50. Adams C, Christospanteus PD, TR EB. Psychopathology, Social and Cognitive Functioning in a Hostel for Homeless Women. Br J Psychiatry. 1996;168:82-6.

51. Fekadu A, Hanlon C, Gebre-Eyesus E, Agedew M, Solomon H, Teferra S, et al. Burden of mental disorders and unmet needs among street homeless people in Addis Ababa, Ethiopia. BMC Med. 2014;12:138.

52. Okamura T, Ito K, Morikawa S, Awata S. Suicidal behavior among homeless people in Japan. Soc Psychiatry Psychiatr Epidemiol. 2014;49:573-82.

53. Prinsloo B, Parr C, Fenton J. Mental illness among the homeless: prevalence study in a Dublin homeless hostel. Ir J Psychol Med. 2012;29(1):22-6.

54. Larney S, Conroy E, Mills KL, Burns L, Teesson M. Factors associated with violent victimisation among homeless adults in Sydney, Australia. Aust N Z J Public Health. 2009;33(4):347-51. 
55. Fischer PJ, Shapiro S, Breakey WR, Anthony JC, Kramer M. Mental health and social characteristics of the homeless: a survey of Mission users. Am J Public Health. 1986;76:519-24.

56. Newton JR, Geddes JR, Bailey S, Freeman CP, McAleavy A, Young GC. Mental health problems of the Edinburgh 'roofless'. Br J Psychiatry. 1994; 165(4):537-40.

57. Bacciardi S, Maremmani AGI, Nikoo N, Cambioli L, Schütz C, Jang K, et al. Is bipolar disorder associated with tramautic brain injury in the homeless? Riv Psichiatr. 2017:52(1):40-6.

58. Goldstein G, Luther JF. GretchenLouiseHaas. Medical, psychiatricanddemographicfactorsassociatedwithsuicidal behaviorinhomelessveterans. Psychiatry Res. 2012;199:37-43.

59. Freeman SJ, Formo A, Alampur AG, Sommers AF. Psychiatric Disorder in a Skid-Row Mission Population. Compr Psychiatry. 1979;20(5):454-62.

60. Bassuk EL, Rubin L, Lauriat A. Is homelessness a mental health problem? Am J Psychiatry. 1984;141:12.

61. Geddes J, Newton R, Young G, Bailey S, Freeman C, Priest R. Comparison of prevalence of schizophrenia among residents of hostels for homeless people in 1966 and 1992. BMJ Open. 1994;308(6932):816-9.

62. Cougnard A, Grolleau S, Lamarque F, Beitz C, Brugere S, Verdoux H. Psychotic disorders among homeless subjects attending a psychiatric emergency service. Soc Psychiatry Psychiatr Epidemiol. 2006;41(11):904-10.

63. Yim LC, Leung HC, Chan WC, Lam MH, Lim WW. Prevalence of mental illness among homeless people in Hong Kong. PLoS One. 2015;10(10):e0140940.

64. Ferrari A, Somerville A, Baxter A, Norman R, Patten S, Vos T, et al. Global variation in the prevalence and incidence of major depressive disorder: a systematic review of the epidemiological literature. Psychol Med. 2013;43(3): 471-81.

65. Fazel S, Khosla V, Doll H, Geddes J. The prevalence of mental disorders among the homeless in Western countries: systematic review and metaregression Analysi. PLoS Med. 2008:5(12):e225.

66. Saha S, Chant D, Welham J, McGrath J. A systematic review of the prevalence of schizophrenia. PLoS Med. 2005:2(5):e141.

67. Moreno-Küstner B, Martín C, Pastor L. Prevalence of psychotic disorders and its association with methodological issues. A systematic review and metaanalyses. PLoS One. 2018;13(4):e0195687-e.

68. Dias M, Gaio R, Sousa P, Abranches M, Gomes M, Oliveira O, et al. Tuberculosis among the homeless: should we change the strategy? Int J Tuberc Lung Dis. 2017;21(3):327-32.

69. Fournier AM, Tyler R, Iwasko N, LaLota M, Shultz J, Greer PJ. Human immunodeficiency virus among the homeless in Miami: a new direction for the HIV epidemic. Am J Med. 1996;100(5):582-4.

70. Sewell DD, Jeste DV, Atkinson JH, Heaton RK, Hesselink JR, Wiley C, et al. HIV-associated psychosis: a study of 20 cases. San Diego HIV neurobehavioral research center group. Am J Psychiatry. 1994;151(2):237-42.

71. Harris MJ, Jeste DV, Gleghorn A, Sewell DD. New-onset psychosis in HIVinfected patients. J Clin Psychiatry. 1991;52(9):369-76.

72. Ayano G, Tulu M, Haile K, Assefa D, Habtamu Y, Araya G, et al. A systematic review and meta-analysis of gender difference in epidemiology of HIV hepatitis B, and hepatitis $C$ infections in people with severe mental illness. Ann General Psychiatry. 2018;17:16.

73. Mayo D, Corey S, Kelly LH, Yohannes S, Youngquist AL, Stuart BK, et al. The role of trauma and stressful life events among individuals at clinical high risk for psychosis: a review. Front Psychiatry. 2017;8:55.

74. Morelli N, Fogler J, Tembulkar S, Graber K, Lincoln SH, Bosquet Enlow M, et al. Potentially traumatic events in youth with and at clinical high risk for psychosis. Early Interv Psychiatry. 2019;13(4):805-9.

75. McGrath JJ, Saha S, Lim CCW, Aguilar-Gaxiola S, Alonso J, Andrade LH, et al. Trauma and psychotic experiences: transnational data from the world mental health survey. Br J Psychiatry. 2017;211(6):373-80.

76. Bechdolf A, Thompson A, Nelson B, Cotton S, Simmons MB, Amminger GP, et al. Experience of trauma and conversion to psychosis in an ultra-high-risk (prodromal) group. Acta Psychiatr Scand. 2010;121(5):377-84.

77. Fischer PJ, Breakey WR. The epidemiology of alcohol, drug, and mental disorders among homeless persons. Am Psychol. 1991;46(11):1115-28.

\section{Publisher's Note}

Springer Nature remains neutral with regard to jurisdictional claims in published maps and institutional affiliations.

Ready to submit your research? Choose BMC and benefit from:

- fast, convenient online submission

- thorough peer review by experienced researchers in your field

- rapid publication on acceptance

- support for research data, including large and complex data types

- gold Open Access which fosters wider collaboration and increased citations

- maximum visibility for your research: over $100 \mathrm{M}$ website views per year

At BMC, research is always in progress.

Learn more biomedcentral.com/submissions 